\title{
COMMUNITY ENGAGEMENT IN SCHOOLS: A GROUNDED THEORY TO UNDERSTAND IN-SERVICE TEACHERS' PRACTICES
}

\author{
Gabriela Monica Assante ${ }^{1}$, Mariana Momanu ${ }^{2}$
}

\begin{abstract}
This exploratory study is guided by the underlying importance of in-service teacher practices in the development of students' community engagement. The main objective is to highlight, describe and understand the role of teachers in the development of community engagement by employing the Grounded Theory methodology. Thirty teachers from urban areas and with at least five years of experience were interviewed to investigate their perspective, approach and practices in promoting community engagement in school settings. The Grounded Theory method was employed in order to develop a descriptive model of the role of teachers in the community engagement development process. Following the open, axial and selective coding process, a theoretical explanation of the process emerged that highlights the pre-conditions of promoting community engagement, conceptualizes the phenomenon, and displays the challenges and educational practices employed. Several categories and sub-categories of the process elements were identified and illustrated by qualitative data. Further, the educational implications of the findings are thoroughly discussed.
\end{abstract}

UDC Classification: 37.04, DOI: https://doi.org/10.12955/pss.v2.196

Keywords: community engagement, in-service teachers, community approach, grounded theory

\section{Introduction}

Trying to define the term 'community' is often problematic because some consider it to be vague and its meaning influenced by one's own beliefs (Head, 2007). Others value a more general approach and even consider it productive. This is based on what Lyon (1987) emphasises concerning the term 'community'. He considers that often the most important concepts in the social sciences are the most imprecise. Due to this feature, it can foster multiple and maybe conflicting perspectives, which in turn can provide growth and development. In varying degrees, it involves a sense of identity, belonging, unity and inclusiveness; however, from a broader perspective, community indicates circumstances in which individuals share something (Gold, 2005). Even if the perspective over what sharing means has different understandings across disciplines such as psychology, education, or sociology, several common grounds can be found of what a community may share, for example, places, emotions, level of training (Schutz, 2006). Being part of a community and further developing an identity within that community influences individuals' power to act in that community (Yonezawa et al., 2009; Wenger, 1998). From a unidimensional perspective, engagement stresses the role of attention, behaviour, cognition or emotions in this context, whereas a multidimensional interpretation of engagement recognises the above-mentioned components of engagement acting simultaneously. Furthermore, Yonezawa et al. (2009) suggest that engagement develops from a critical dimension and incorporates the role of concepts such as context, identity and criticality in framing the concept of engagement. Recent approaches to community aim for increased individual engagement and active participation in an array of socio-political inquiries. These engagement and participatory processes include a variety of guiding principles, strategies and practices. The participation of community members in the dynamic process of identifying and solving social problems can take an abundance of forms and cover a wider range of domains (Head, 2007). Community engagement aims to positively engage the community in achieving and implementing proper outcomes for the emerging issues. It implies a collaborative working process between individuals affiliated by physical proximity, interest or similarity of the tackled issue. Community engagement aims to address the specific issues that negatively impact individuals' wellbeing. As a strong means to ensure environmental and social changes, it is meant to improve the quality of life of the entire community (Centers for Disease Control and Prevention, 1997).

It is important to consider the diversity that exists within any community. Therefore, linking the terms 'community' and 'engagement' serves to shift the focus from the individual to the collective and the associated implications for inclusiveness.

The need to develop and implement sustained and comprehensive relationships between schools and the community is a powerful area of interest for both schools and researchers (Molina, 2013). There is no unique guideline that can prescribe a suitable approach applicable in all contexts and settings that develop strong links between schools and communities and, at the same time, overcome the challenges

\footnotetext{
${ }^{1}$ Alexandru Ioan Cuza University, Iași, Romania, panzaru.monica@yahoo.com

${ }^{2}$ Alexandru Ioan Cuza University, Iași, Romania, momanu@uaic.ro
} 
of every situation. Untangling the dynamics of these relationships is a complicated process that requires attention; however, more importantly, there is a strong unifying desire to link schools and communities together. This purpose needs to be fulfilled in relation to the identified needs and resources. Developing a powerful partnership will provide academic, social and emotional support for children (Henderson \& Mapp, 2002).

Ideally, the development of community engagement should enable students to acquire meaningful knowledge about social, political and economic structures. Furthermore, this should help them identify the strengths and challenges of their social environment. Knowledge should favour the development of skills related to engaging in community actions, such as identifying social issues and acting to transform their social reality. Schools and teachers are in a unique position to influence students' community and civic engagement. Moreover, young people spend the largest amount of their time in school from age 6 to 17 , allowing an opportunity to achieve community engagement goals through the development of knowledge, attitudes and behaviour among different social groups (Torney-Purta, 2002). Considering the wide variety of educational practices, the present inquiries refer to the approaches engaged by teachers to promote students' community engagement. Therefore, this exploratory study proposes the following lines of investigation: How are the community engagement goals embedded in school curricula? What educational strategies do teachers use to develop students' community engagement? The primary method used for investigating the socio-educational aspects was Grounded Theory (Glaser \& Strauss, 1967), which represents a qualitative research method orientated towards promoting the systematic collection and analysis of the data and allowing the formulation of a theoretical explanation for the studied phenomenon.

\section{Method}

The present study focused on teachers' views and perspectives on community engagement educational practices and the meanings assigned to their personal experience, therefore, a qualitative research design was considered the most suitable research approach (Daher, Carré, Jaramillo, Olivares \& Tomicic 2017). Given the main research purpose of uncovering teachers' understandings, educational practices, and teaching strategies used in the process of promoting community engagement, an inductive research approach was used. Specifically, Grounded Theory (GT) which informs specific procedures for systematic data collection and data analysis (Charmaz 2001). Developed by Glasser and Strauss (1967), Grounded Theory (GT) is widely employed in educational sciences. This methodology offers specific directions on coding, categories and themes all of which are developed inductively and anchored directly in the data. Further, GT provides the opportunity to develop a theoretical explanation of the studied phenomenon from conceptualizing qualitative data.

\section{Participants}

Thirty in-service teachers representing various field areas participated in the study. The main selection criterion consisted of the educational level in which the teachers were practicing: middle-school or highschool. The sample included 25 women aged 25- to 65-years-old and 5 men aged 38- to 55-years-old. The method used for sampling was the snowball technique: teachers were recommended by colleagues from the local schools situated in the North-East region of Romania. The subjects which were taught varied. Eleven teachers taught language and literature, four taught mathematics, three foreign languages, three physical education and sports, two religion, one taught geography, one physics, one chemistry, one counselling and guidance, one psychology and two taught art. The reported teaching experience varied from 5 to 35 years.

\section{Procedure}

The study participants were at first, contacted by phone and asked to participate in the research. A semistructured interview guide was developed to explore the participants' educational practices for promoting students' community engagement. The interview guide consisted of three open-ended questions, investigating the process of promoting community engagement in schools. The interview questions had two main focus areas: teachers' educational practices in promoting students' community engagement and the teachers' views on the relevant factors in developing community engagement. Therefore, the interviews addressed two main issues: teachers' views on community engagement and the teaching educational practices and methods used for promoting community engagement. The interviews were audio-recorded, and the recordings transcribed. The interview duration ranged from 20 
to 52 minutes. An objectivist approach to Grounded Theory was used, which formulates codes, categories, and themes determined by the data (Charmaz 2001). The semi-structured interviews were transcribed, and open, axial and selective coding was conducted. After extracting the codes, categories, and themes, several links emerged between phenomena during the selective coding process. This step supported a theoretical explanation of the phenomena to be formulated. The process of broadening the categories is a circular one; if the new data do not fit within the initial categories, then new broader categories have to be identified to include all data. This comparison process advances until it reaches a level of saturation. The requirement is to be as open as possible to new ideas even if the data does not fit former assumptions, models, and theories for avoiding confirmation bias. The data represented by the transcribed interviews were organised and imported into MAXQDA. Its usefulness resides in facilitating the data organization process in terms of assigning coding and themes and writing memos to help data analysis.

\section{Results}

The framework provided by Strauss and Corbin (1990) helped in developing the Grounded Theory model for promoting community engagement in middle-school and high-school students. The theoretical explanation that emerged from the present investigation is reported in Figure 1. In promoting students' community engagement, certain preconditions are required, which in turn will influence the development of community engagement under two main aspects: environmental practices and helping the poor. At this point, several challenges can occur, which in turn will influence both the development of community engagement and the educational practices employed.

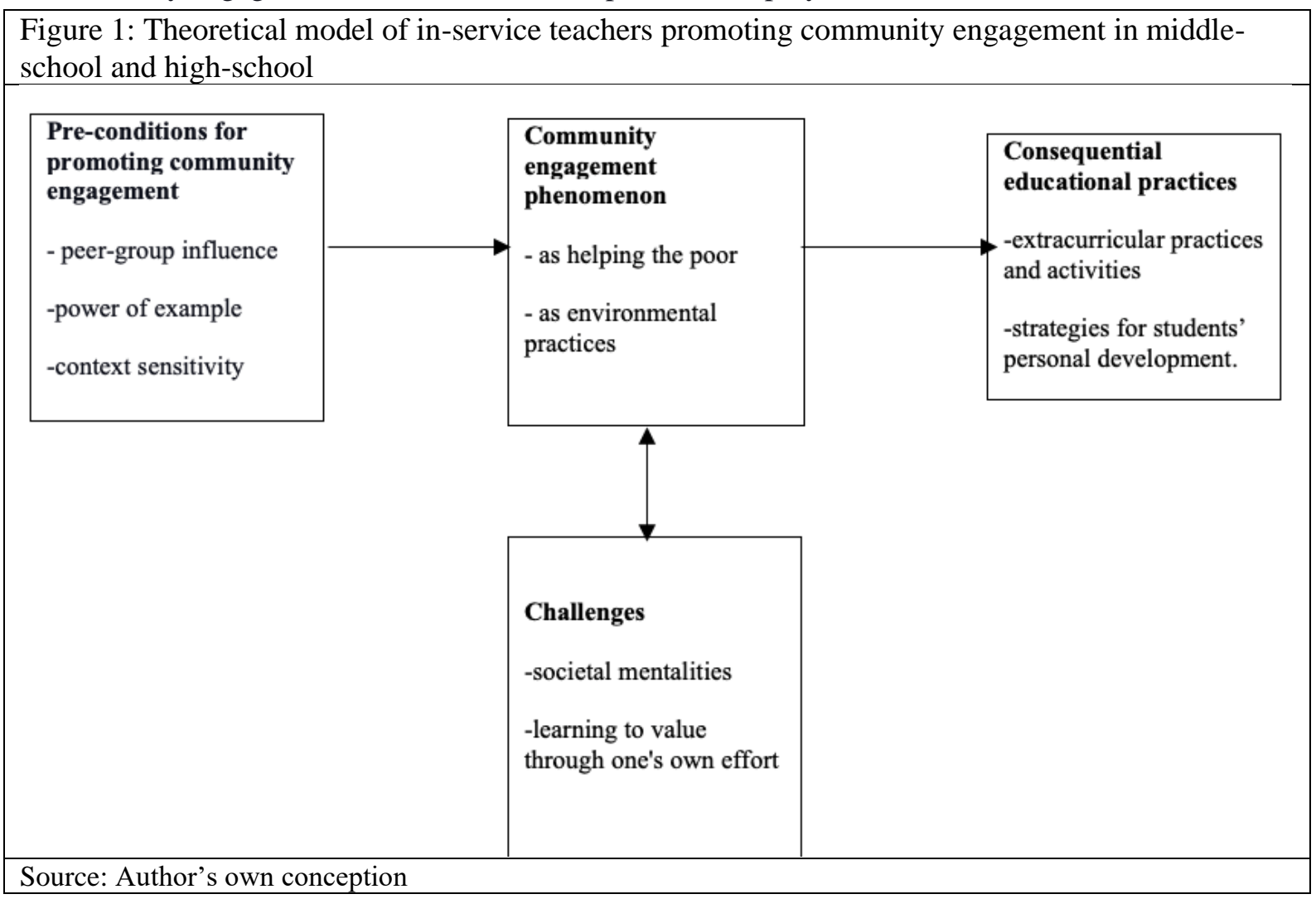

Pre-conditions for promoting community engagement

For promoting community engagement in schools, three core categories of preconditions emerged from the data that influenced the phenomenon including the practices employed in developing students' engagement in the community such as the power of example, peer-group influence and sensitivity to context. The power of example represents a fairly inclusive category as it includes the necessity for good practice examples from inside the family, teachers, members of the religious community and other members of the community such as neighbours or friends. Therefore, as one foreign language teacher stresses, "This behaviour comes from the family, not necessarily from us. If a parent goes and throws some garbage on the street, then the children will do the same; no matter how much we explain to them, 
a behaviour seen at home matters more than what we tell them. Yes, I was involved in ecology-related projects ... even if we explain at school; this thing must be very clear in their family practices". Another teacher explains that everyone has to do their part in order to have a well-developed sense of community, stating: "I think that if they saw adults, and I don't necessarily mean their parents. I believe that if they saw anyone on the street behaving appropriately in the community, the child would then automatically change his behaviour as well". Moreover, teachers believe that the good examples must come also from the religious community; for example, one foreign language teacher strongly affirms that „the Church should be actively involved" in promoting good practices for community engagement. Further, in setting the stage for promoting community engagement with positive results the peer-group pressure and influence it becomes relevant, especially in maintaining the good practices. One mathematics teacher states that "if their group is large enough, there is a large possibility for the good practices to be maintained in the long-run". A recent study (Vollet, Kinderman \& Skinner, 2017) supports our findings but also shows cumulative effects. Under these effects, both teacher involvement and peer group engagement predicted changes in students' engagement. The authors also suggest that peer groups and teachers are individually important; hence, an examination of their joint effects is needed to understand their contributions. Our findings also suggest the importance in this process of good practice examples from the family and other community members. Another important category that is more related to individual characteristics is one's sensitivity to context. Being sensitive to contextual aspects is reported to be a relevant characteristic in developing community engagement. One literature teacher stresses that "putting children in the situation to empathise with others" will lead to a better engagement in community actions.

\section{Community engagement phenomenon}

The results show that the community engagement phenomenon is mainly seen as helping the poor and promoting environmental practices. These seem to be the principal concerning elements in the studied cultural context. Considering the impact of poverty on individual development is understandable, that at least until now, the concept of community engagement mainly includes helping those in need and has not been assimilated to the idea of active citizenship. One teacher says that before all National Holidays "we collect food and clothes, and donate them to those in need. We clean the schoolyard and the surroundings; we sanitize all these places". In general, the actions towards helping those in need took place before major National Holidays when people seemed more inclined and willing to help others. In this sense, another literature teacher states that "before Christmas, we always go to an old people's home, students give them presents and we sing carols". On the other hand, ecological practices are more likely to take place during the week dedicated to extracurricular activities.

\section{Challenges in promoting community engagement}

Several challenges need to be overcome to achieve the students' community engagement around the aspects previously mentioned. In this category, we include several societal mentalities and the need for learning to value through one's effort. For example, regarding societal mentalities, one literature teacher states that students frequently ask "why should I do it if others do not?" Further, he continues "children in my classes are not allowed to compare themselves to something a classmate does or does not do". A recent experiment (Krupka \& Weber, 2009) shows that observing others engaging in pro-social behaviour leads to increased pro-social behaviour in the observer. On the other side of the argument, our results show that observing others not engaging in positive community practices will lead to decreased community engagement. This indicates a type of diffusion of responsibility of children, which might suggest that there must be put an emphasis on moral education. The problem is that when everyone is responsible, nobody assumes individual responsibility. Hence, group action is an expedient for weakening moral control. In other words, any harm done by a group can always be attributed largely to the behaviour of others (Bandura et al., 1996). Moreover, partially to overcome the previous challenge, there is an observed need for children to learn value through one's effort. A geography teacher states that children must be taught to learn about the value of things: "they must be taught that someone invested time, and work, and time in preparing something for them, in such a pleasant setting with a short artistic program, with the involvement of volunteers and students, I do not remember from which university. But they kept mocking everything. They weren't focused on seeing the message being sent to them" and, this can only be achieved if they are directly implicated in the community actions process. 


\section{Consequential educational practices}

Consequently, two remedial directions surface in the form of extracurricular practices and activities for promoting community engagement and strategies for students' personal development. The extracurricular activities entail mainly ecological practices and helping the less fortunate while the selfdevelopment strategies aim to develop students' empathy and a sense of responsibility. Extracurricular practices include pro-social and environmental activities, charity and volunteering and solving urgent community issues. It represents a current practice whereby during the one week allocated in the curriculum for activities outside the school, teachers organise different practical activities that aim to promote community engagement. These activities are meant to introduce children to community issues and make contact with different realities. During this time, children "are encouraged to take humanitarian actions and make visits to all kinds of humanitarian institutions". It seems that community activities are more common during this school period and before holidays. The main strategies used for students' self-development include extrinsic motivation strategies, exercises of will and vicarious moralization. A foreign language teacher says she always used educational material to fire the enthusiasm of her students and, in this way to increase their motivation- "It matters a lot how the teaching material is put into practice", she says. On the same note, an arts teacher says that she uses several types of learning materials "with topics that raise awareness". In terms of exercising ones' will, the 'small steps' method is applied; for example, "let's try to take notes from Monday to Friday regarding the positive actions from that week".

\section{Conclusion}

The present findings emphasise the principal components of developing community engagement in school settings. In the studied cultural context, the concept of community engagement is mainly assimilated to the idea of helping the poor and ecological practices. But still, for achieving these results, certain requirements must be met. Students need examples of good practice, they need positive peergroup influence and to develop sensitivity to context. The results also show that this process is not straightforward: several challenges must be overcome to obtain satisfactory results. In this category, we mention several societal mentalities and the need to learn to value things through their own effort. The mentality of children indicates a type of diffusion of responsibility, which might suggest an emphasis must be put on moral education. When everyone is responsible, no one feels responsible. Group action is still another expedient for weakening moral control. Any harm done by a group can always be attributed largely to the behaviour of others (Bandura et al., 1996). To overcome these challenges, teachers can choose two strategies. First, they can use several extracurricular practices and activities to promote mainly pro-social and ecological behaviour. Second, several self-development strategies are employed to develop empathy, the power of will, motivation and responsibility. These aspects are considered relevant in maintaining good practices in the long-term. Considering these findings, teachers must design classroom environments that overcome all sorts of obstacles while, in this case, also focusing on students' self-development. These results suggests that there is an acute need to develop community engagement in a broader, more comprehensive and inclusive manner that includes other aspects of social reality such as community health and active citizenship. As the results indicate, to achieve this objective, the involvement of all members of the community is required and this cannot fall only under the responsibility of the teachers and the context of the school. This study focused on the actual educational practices and strategies used by teachers to promote students' community engagement. The findings presented from this study encourage a close examination of current teaching practices within a framework for developing new educational policies. In addition, the results of this research appoint future lines of investigation primarily in the direction of developing a broader scope of the community engagement concept and in examining the possibility to promote community engagement and active citizenship.

\section{Acknowledgement}

This work was co-funded by the European Social Fund, through Operational Programme Human Capital 2014-2020, project number POCU/380/61131123623, project title $<<\mathrm{PhD}$ Students and Postdoctoral Researchers Prepared for the Labour Market!>>.

\section{References}

Bandura, A., Barbaranelli, C., Caprara, G. V., \& Pastorelli, C. (1996). Mechanisms of moral disengagement in the exercise of moral agency. Journal of personality and social psychology, 71(2), 364, https://doi.org/10.1037/0022-3514.71.2.364. 
Centers for Disease Control and Prevention (1997). Principles of community engagement. CDC/ATSDR Committee on Community Engagement, 13.

Charmaz, K. 2001. Grounded theory: Methodology and theory construction. In International encyclopedia of the social \& behavioral science, edited by N.J Smelser and P.B. Baltes, 6396-6399. Oxford: Pergamon, https://doi.org/10.1016/B0-08043076-7/00775-0.

Daher, M., D. Carré, A. Jaramillo, H. Olivares, and A. Tomicic. 2017. "Experience and Meaning in Qualitative Research: A Conceptual Review and a Methodological Device Proposal.” Forum: Qualitative Social Research, 18(3). https://doi.org/10.17169/fqs-18.3.2696.

Glaser, B.G. and A.L. Strauss. (1967). The Discovery of Grounded Theory: Strategies for Qualitative Research. Chicago: Aldine.

Gold, A. G. (2005). Conceptualizing Community: Anthropological Reflections a Background Paper for The Collaborative Initiative for Research Ethics in Environmental Health. Moynihan Institute for Global Affairs, Syracuse University May.

Head, B. W. (2007). Community engagement: participation on whose terms? Australian Journal of Political Science, 42(3), 441-454, https://doi.org/10.1080/10361140701513570.

Henderson, A. T., \& Mapp, K. L. (2002). A new wave of evidence: The impact of school, family and community connections on student achievement. Austin, TX: Southwest Educational Development Lab.

Krupka, E., \& Weber, R. A. (2009). The focusing and informational effects of norms on pro-social behavior. Journal of Economic psychology, 30(3), 307-320, https://doi.org/10.1016/j.joep.2008.11.005.

Lyon, L. (1987). The Community in Urban Society. Chicago: Dorsey Press.

Schutz, A. (2006). Home is a prison in the global city: The tragic failure of school-based community engagement strategies. Review of educational research, 76(4), 691-743, https://doi.org/10.3102/00346543076004691.

Strauss, A., and J. Corbin. 1990. Basics of qualitative research: Grounded theory procedures and techniques. Newbury Park, Ca: Sage.

Torney-Purta, J. (2002). The school's role in developing civic engagement: A study of adolescents in twenty-eight countries. Applied developmental science, 6(4), 203-212, https://doi.org/10.1207/S1532480XADS0604_7.

Vollet, J. W., Kindermann, T. A., \& Skinner, E. A. (2017). In peer matters, teachers matter: Peer group influences on students' engagement depend on teacher involvement. Journal of Educational Psychology, 109(5), 635, https://doi.org/10.1037/edu0000172.

Wenger, E. (1998). Communities of practice: Learning, meaning and identity. Cambridge, England: Cambridge University Press.

Yonezawa, S., Jones, M., \& Joselowsky, F. (2009). Youth engagement in high schools: Developing a multidimensional, critical approach to improving engagement for all students. Journal of Educational Change, 10(2), 191-209, https://doi.org/10.1007/s10833-009-9106-1. 